\title{
Exportações de produtos agrícolas e o ambiente portuário: a perspectiva da teoria dos custos de transação
}

\author{
Exports of agricultural products and the port environment: the perspective of the \\ transaction costs theory
}

\author{
Maria Carolina de Paulo Esteves ${ }^{1}$ (D), Andréa Leda Ramos de Oliveira ${ }^{1}$ (D), Ana Paula Milanez ${ }^{2}$ (D) \\ ${ }^{1}$ Universidade Estadual de Campinas (UNICAMP), Campinas (SP), Brasil. E-mail: carolinadepaulo@gmail.com; \\ aleda@unicamp.br \\ ${ }^{2}$ Universidade Tecnológica Federal do Paraná (UTFPR), Ponta Grossa (PR) Brasil. E-mail: apmilanez@utfpr.edu.br
}

Como citar: Esteves, M. C. P., Oliveira, A. L. R., \& Milanez, A. P. (2020). Exportações de produtos agrícolas e o ambiente portuário: a perspectiva da teoria dos custos de transação. Revista de Economia e Sociologia Rural, 58(1), e192957.

https://doi.org/10.1590/1806-9479.2020.192957

\begin{abstract}
Resumo: O cenário portuário brasileiro passou por diversas mudanças ao longo das últimas décadas, desde a descentralização das atividades até novos critérios para a exploração e arrendamento para a iniciativa privada de terminais de movimentação de carga em portos públicos. Estas transformações tiveram impacto na dinâmica de exportação dos produtos agrícolas e nos custos de transação. Isso posto, este trabalho busca identificar se existem custos de transação no ambiente portuário para a exportação de produtos agrícolas e a proposição de um índice de custo de transação (ICT). As movimentações de dois importantes produtos agrícolas foram analisadas: soja e etanol. A dimensão avaliada das transações foi a especificidade dos ativos. Os resultados indicaram que o maior ICT obtido foi para o etanol. Contudo, os ativos avaliados para ambos produtos apresentaram especificidades que variaram entre média e alta, o que permitiu concluir que no setor portuário os custos de transação envolvidos são altos, promovendo a adoção de novas estratégias e formas de governança para mitigar o risco associado às transações, como os contratos de longo de prazo e de parcerias.
\end{abstract}

Palavras-chaves: Nova Economia Institucional, logística, agronegócio.

\begin{abstract}
The Brazilian port scenario has undergone several changes over the last decades, from the decentralization of activities to new criteria for exploration and leasing for the private initiative of cargo handling terminals in public ports. These changes had an impact on the export dynamics of agricultural products and on transaction costs. This paper seeks to identify if there are transaction costs in the port environment for the export of agricultural products and the proposal of a transaction cost index (ICT). The handling of two important agricultural products were analyzed: soy and ethanol. The dimension of the analyzed transactions was asset specificity. The results indicated that the highest ICT obtained was for ethanol. However, the assets evaluated for both products had specificities that varied between average and high, which allowed concluding that in the port sector the transaction costs involved are high, promoting the adoption of new strategies and forms of governance to mitigate the risk associated with the transactions, such as long-term contracts and partnerships.
\end{abstract}

Keywords: New Institutional Economics, logistics, agribusiness.

\section{Introdução}

O Brasil está entre os líderes em exportação de produtos agropecuários e se mantém no topo do ranking de exportação de produtos como: café, açúcar, etanol de cana-de-açúcar, suco de laranja e complexo de soja (farelo, óleo e grão). A previsão do Ministério da Agricultura é de que, até 2030, um terço dos produtos agrícolas comercializados sejam brasileiros, por conta da crescente demanda dos países asiáticos (Brasil, 2013b). 
Grande parte das exportações de commodities passa pelo porto de Santos (São Paulo), que é o maior porto da América Latina. Em 2016, as movimentações no porto de Santos atingiram aproximadamente 113,8 milhões de toneladas, com forte influência dos embarques de produtos agrícolas ( $28 \%$ das movimentações) com destaque para açúcar, soja grão, milho, farelo de soja e sucos cítricos. As movimentações de produtos agrícolas totalizaram 31,5 milhões (Companhia Docas do Estado de São Paulo, 2016).

Apesar da intensidade das atividades de exportação no porto de Santos, o processo de escoamento encontra falhas estruturais e de planejamento, o que tem ocasionado diversas filas de caminhões e longa espera de navios para embarcar. De acordo com o relatório Global Competitiviness Report 2016-2017 (Schwab, 2016), o Brasil ocupa a 114 colocação entre 138 países em infraestrutura portuária. Isso mostra que, apesar da expressiva participação no comércio mundial, são necessários investimentos para a superação dos gargalos.

Segundo Hilsdorf \& Nogueira Neto (2016), os caminhões carregados com açúcar levam cerca de 12 horas para descarregar, e o ideal é que esta operação seja feita entre três e quatro horas. Além de a morosidade no descarregamento implicar em filas de caminhões para desembarque, há o problema que envolve o tempo de espera dos navios para atracação em Santos. Em 2012, a fila durava 16 horas, quase três vezes o tempo que se gastava em 2003 (seis horas), enquanto o total de estadia das embarcações no porto passou de 26 para 35 horas no mesmo período.

Com vistas a contribuir com a tarefa de encontrar elementos que auxiliem no direcionamento de arranjos logísticos de exportação mais eficientes, é necessário analisar os custos de transação do ambiente portuário. Avaliando os custos de transação inerentes às atividades portuárias, é possível verificar quais os melhores arranjos contratuais para determinada transação, objetivando, assim, a redução dos custos.

Ademais, a avaliação dos custos de transação no ambiente portuário pode contribuir para o interesse de investimentos no setor portuário, que tem tido sua configuração alterada desde 2003, quando a Lei de Modernização dos Portos (Lei n. 8.630/93) foi implementada e seguida pelo novo marco regulatório (Lei n. 12.815/2013), possibilitando novos modelos de arranjos contratuais.

Há uma base de estudos sobre Custos de Transação bastante rica, iniciando a partir de Coase (1937) em "A Teoria da Firma", em que apresentou o tema das instituições dentro do contexto da teoria econômica. Coase (1937) observou que, às vezes, o custo de gerenciar transações econômicas por meio de mercados é maior do que o custo de gerenciar as transações econômicas dentro das organizações. Anos após a publicação de Coase (1937), Williamson deu andamento aos estudos sobre custos de transação.

A transação nada mais é que o processo de transformação de um determinado produto através de interfaces tecnologicamente separáveis. Tendo como finalidade a redução dos custos de transação, os agentes podem se utilizar de mecanismos capazes de regular uma transação, os quais são denominados "estruturas de governança" (Williamson, 1985).

A proposição básica é de que cada forma de governança, isto é, via mercados, formas híbridas ou hierarquia (integração vertical) deve estar suportada por determinado tipo de contrato. A opção das firmas pela forma de coordenação mais adequada é feita a partir da análise de três parâmetros da transação: a especificidade dos ativos envolvidos na transação, a frequência e a incerteza (Belik, et al. 2007).

Nesse sentido, o objetivo da TCT é estudar as características dos custos de transação como indutores de modos alternativos de organização da produção pelas firmas, ou seja, sua governança, dentro de um quadro de análise institucional (Zylbersztajn, 1996, 2014).

Isso posto, o objetivo deste trabalho foi avaliar se existe a ocorrência dos custos de transação no ambiente portuário. Além disso, é proposta a criação de um Índice de Custos de Transação (ICT) tendo como elemento-chave a especificidade dos ativos envolvidos na exportação de soja e etanol. Este índice pode ser utilizado para auxiliar a tomada de decisão de agentes exportadores no desenho da forma de governança mais indicada.

A hipótese desta pesquisa é a de que quanto maior a especificidade dos ativos da atividade de exportação, maiores serão os custos de transação envolvidos nas saídas para o mercado internacional, implicando na necessidade de contratos de longo prazo mais elaborados. 
Estudos propostos por Martins et al. (2010) e Oliveira (2011) foram no mesmo sentido. Martins et al. (2010) avaliou a ocorrência de custos de transação e seus impactos no planejamento logístico para exportação do café, tomando-se como unidade de análise a transação de café de uma empresa exportadora. Oliveira (2011), por sua vez, avaliou os custos de transação no setor ferroviário para a movimentação de quatros produtos agrícola (soja, farelo de soja não transgênico, açúcar e etanol).

Quanto ao setor portuário, é preciso mencionar que este vem passando por diversas mudanças ao longo das últimas décadas, em especial após a Lei de Modernização dos Portos (Lei n. 8.630/93) (Brasil, 1993) e o novo marco regulatório (Lei n. 12.815/2013) (Brasil, 2013a), com novos critérios para a exploração e o arrendamento (por meio de contratos de cessão para uso) para a iniciativa privada de terminais de movimentação de carga em portos públicos. Além disso, as novas regras facilitam a instalação de novos terminais portuários privados. Para Farranha et al. (2015), um dos objetivos principais da Lei n. 12.815/2013 foi proporcionar mais agilidade e modernizar o setor, reduzindo os custos das transações.

\section{Fundamentação teórica}

As instituições são as regras do jogo em uma sociedade ou, mais formalmente, são as restrições humanamente concebidas que moldam a interação humana. Em consequência, elas estruturam incentivos no intercâmbio humano, sejam políticos, sociais ou econômicos. A mudança institucional ajusta o modo como as sociedades evoluem ao longo do tempo e, portanto, é a chave para a compreensão da mudança histórica (North, 1990).

As instituições constituem-se como um conjunto de regras construídas pelos seres humanos que estruturam a interação social, econômica e política. Elas podem ser regras formais (constituições, leis e direitos de propriedade) e/ou informais (costumes, tradições, tabus e códigos de conduta) (Oliveira, 2011).

North (1990), ao escrever sobre a importância das instituições na economia, descreve que elas afetam o desempenho da economia pelo seu efeito nos custos de troca e produção, em que, juntos à tecnologia empregada, determinam os custos de transação e transformação, constituindo, assim, os custos totais.

O conceito de que as instituições afetam o desempenho das economias é pouco controverso, assim como o de que este desempenho é fundamentalmente influenciado pela forma como as instituições evoluem (North, 1990).

O estudo precursor para o entendimento dos custos de transação foi realizado por Ronald Coase, que introduziu este tema em seu artigo "The Nature of the firm", em 1937. Neste estudo, o autor descreve a firma como um instrumento para atuar nos mercados com o intuito de diminuir os custos de transação e de contratos.

A partir dos estudos de Coase (1937) e North (1990), iniciou-se uma corrente de estudos denominada Nova Economia Institucional (NEI). O objetivo fundamental da nova economia institucional, também denominada de Teoria dos Custos de Transação (TCT), é o de estudar o custo das transações como o indutor dos modos alternativos de organização da produção (governança), dentro de um arcabouço analítico institucional (Zylbersztajn, 1996).

Uma das formas de entender o desempenho das organizações é a análise dos Custos de Transação, considerada por Williamson (1979) fundamental para o estudo da economia, em que os Custos de Transação identificam as dimensões críticas para caracterizar as transações, descreve as principais estruturas de governança das transações e indica como e por que as transações podem ser combinadas com as instituições de forma discriminatória.

Numa estrutura de governança, o objetivo é garantir uma coordenação (com ou sem o mercado) que economize os custos de transação e reduza a incerteza, compensando os agentes da racionalidade limitada e do oportunismo (Belik et al., 2007). Assumindo que nas transações, sejam elas via mercado ou internas, existem custos, Williamson (1993) destaca que, para entender o conceito da Teoria dos Custos de Transação (TCT), é necessário destacar dois pressupostos comportamentais: racionalidade limitada e oportunismo.

Racionalidade limitada é o pressuposto de que o agente não possui todas as informações necessárias para a transação e, sendo assim, o ator humano é considerado limitadamente racional. Para fins de TCT, a ramificação-chave da racionalidade limitada para o estudo do 
contrato é que todos os contratos complexos são inevitavelmente incompletos. A ficção analiticamente conveniente da contratação completa é assim desautorizada (Williamson, 2007)

O outro pressuposto comportamental é o oportunismo: a ideia essencial é a de que, na busca do seu autointeresse, os homens nem sempre se conduzem de maneira transparente e honesta. Para Williamson (1993), o oportunismo não condiz apenas às falhas em autorrevelar atributos verdadeiros ex-ante (seleção adversa) e verdadeiro desempenho ex-post (risco moral), mas o fracasso em dizer a verdade e em se admitir que os agentes econômicos podem mentir, trapacear, roubar e violar o espírito de um acordo. Ademais, são admitidas as possibilidades de os agentes econômicos induzirem deliberadamente a quebra de contrato e se envolverem em outras formas de comportamento estratégico (Williamson, 1993).

Para que a redução de Custos de Transação seja possível por meio de uma estrutura de governança, as empresas podem optar por três tipos de estrutura: 1) via mercados; 2) formas híbridas e 3) hierarquia (integração vertical). Esta escolha é baseada na análise dos parâmetros das transações contratuais observadas por Williamson (1985): a especificidade dos ativos envolvidos na transação, a frequência e a incerteza.

O conceito de incerteza é relacionado com pressuposto comportamental do oportunismo e, de acordo com Azevedo (2000), a incerteza aumenta as lacunas de informações que os contratos não podem cobrir, portanto, neste ambiente, os agentes sem posse das informações necessárias não podem prever os acontecimentos futuros, aumentando as possibilidades de renegociação e possíveis perdas.

A frequência de uma transação também é considerada na escolha da estrutura de governança, visto que, quanto maior a frequência, menores os custos associados à coleta de informações e elaboração de um contrato complexo, além de que os agentes não terão motivos para impor perdas aos seus parceiros. Em transações recorrentes, as partes podem desenvolver reputação, o que limita seu interesse em agir de modo oportunista para obter ganhos de curto prazo (Oliveira, 2011).

Por último, a especificidade dos ativos envolvidos é um dos parâmetros mais importantes, sendo considerada uma variável-chave para a determinação da estrutura de governança. Quanto mais específico um ativo, assume-se que maiores serão os custos de transação envolvidos e, segundo Azevedo (2000), os ativos são específicos quando o retorno relacionado a eles depende da continuidade de uma transação.

Williamson (1991) e Neves et al. (2001) apontam que a especificidade de ativos pode ser considerada em seis diferentes tipos, sendo eles:

- Especificidade local: refere-se ao espaço geográfico necessário para utilização do ativo, ou seja, o ativo perde valor no caso de deslocamento;

- Especificidade física: refere-se aos ativos envolvidos durante a produção de um determinado produto a ser transacionado. O ativo possui limitação de uso, seriam máquinas e equipamentos específicos para um determinado processo produtivo e as características exclusivas de um determinado ativo podem não ter valor em outra aplicação;

- Especificidade humana: relacionada aos recursos humanos necessários para realização de uma determinada atividade, ou, ainda, conhecimento acumulado sobre uma determinada atividade;

- Especificidade tecnológica: a empresa, para poder realizar a transação, precisa investir em determinados processos tecnológicos, como em tecnologia da informação (troca eletrônica de dados, gestão de estoques, planejamento da logística).

- $\quad$ Especificidade de marca: relaciona-se à reputação que o nome da empresa ou produto tem no mercado, ocorre quando se exige que uma marca específica represente todos produtos advindos da cadeia de suprimentos;

- $\quad$ Especificidade temporal: está presente quando um determinado produto apresenta características de perecibilidade ou qualquer outra condição que implique na necessidade de consumo em um determinado período de tempo e, ainda, o tempo envolvido no desenrolar da transação pode implicar em perda de valores transacionados. 
Considerando-se os diferentes tipos de especificidades de ativos, ao pensar sobre os custos de transação, quanto maior a especificidade dos ativos, maior a perda associada a uma ação oportunista por parte de outro agente. Consequentemente, maiores serão os custos de transação (Azevedo, 2000).

Se a especificidade dos ativos for nula, os custos de transação serão negligenciáveis, não havendo necessidade de controle sobre a transação. Nesse caso, a forma organizacional mais eficiente seria o mercado. Se, ao contrário, a especificidade de ativos for elevada, os custos associados ao rompimento contratual serão altos. Neste caso, é interessante um maior controle sobre as transações, mesmo que às custas de menor motivação. Opta-se, portanto, pela hierarquia (integração vertical) (Azevedo, 2000).

A decisão das empresas de qual estrutura de governança é mais adequada se dá com base na avaliação dos três parâmetros da transação, sendo eles: a especificidade dos ativos, a frequência e a incerteza (Figura 1).

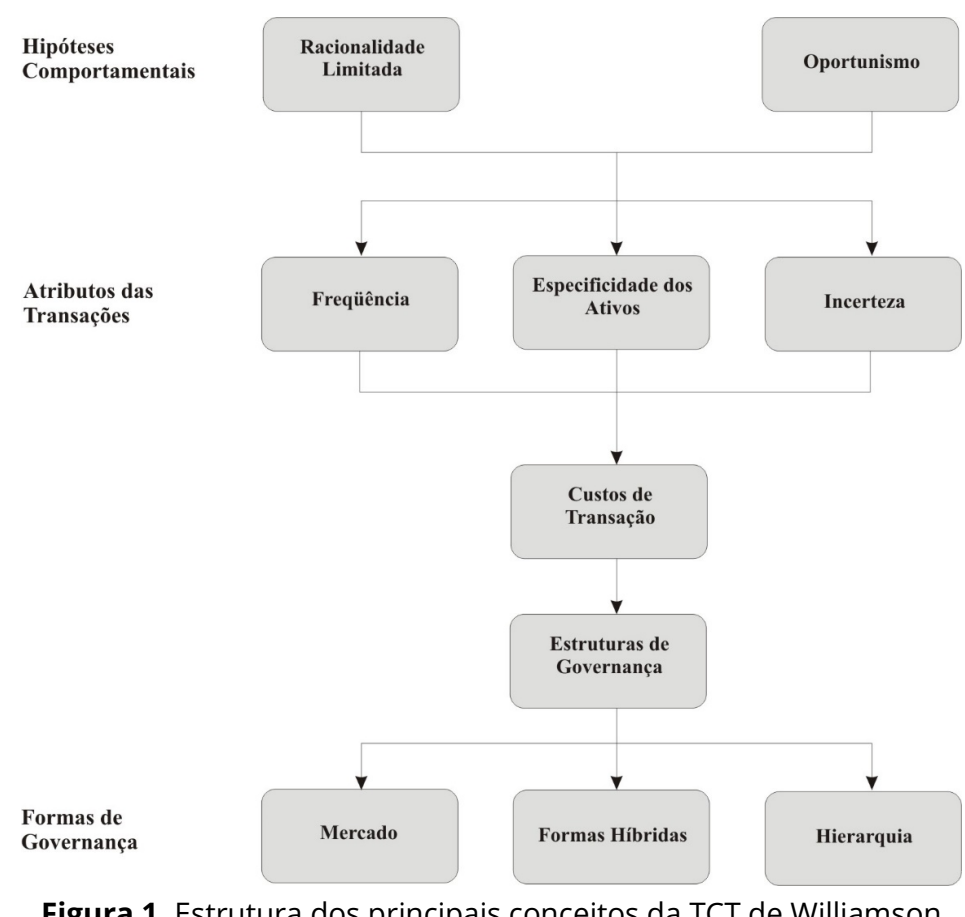

Figura 1. Estrutura dos principais conceitos da TCT de Williamson Fonte: Belik et al. (2007, p. 117).

Apesar de ser reconhecida a importância dos Custos de Transação pelas organizações e agentes econômicos, os esforços dos estudos atuais se concentram na aplicação da Teoria dos Custos de Transação (TCT) no ambiente empresarial, com o intuito de identificar, analisar e compor bases para a tomada de decisão das organizações. Alguns trabalhos mais recentes envolveram a proposição de modelos analíticos para sistemas agroindustriais à luz da TCT, permitindo testar hipóteses a respeito da organização dos sistemas como Fernandes (2009), Ji et al. (2012) e Nuintin et al. (2012). Nesta mesma linha, a TCT também foi aplicada para entender sua influência na escolha do mecanismo de comercialização mais adequado em Leme \& Zylbersztajn (2008), Martins et al. (2010) Oliveira (2011), Fragoso (2013) e Weseen et al. (2014). No entanto, é preciso avançar na construção de parâmetros comparativos, sendo essa uma das motivações para o desenvolvimento do presente trabalho.

Com relação a estudos empíricos e aplicados, Zylbersztajn (1996) propõe um modelo analítico para sistemas de agribusiness, em especial do mercado de café, com base na Teoria dos Custos de Transação (TCT). Este trabalho concluiu que a TCT permite formular e testar hipóteses a respeito da organização de sistemas em geral e de agribusiness em particular, com possibilidades de aplicação em coordenação e competitividade de sistemas produtivos.

Diversos fatores, como mercado, economia e cultura organizacional, fazem parte de um pacote de requisitos para a escolha da estrutura de governança de uma organização e, além 
destes parâmetros, os custos de transação passam a ter papel importante no ambiente competitivo, em que a redução dos custos de produção e transação é extremamente estratégica.

Um exemplo desta abordagem é o trabalho de Nogueira \& Bataglia (2012), em que foi avaliada a influência dos Custos de Transação e das competências organizacionais na escolha da estrutura de governança no sistema de produção em seu estágio de manufatura.

Dentre as dimensões da TCT, a especificidade dos ativos é considerada a dimensão de maior peso, pois indica o potencial de perda de investimentos incorridos em uma transação, se isso não ocorrer. Nesta abordagem, a estrutura de governança adotada é o resultado de uma escolha racional para minimizar os custos de transação, principalmente devido ao risco de comportamento oportunista pela contraparte em uma transação (Nogueira \& Bataglia, 2012).

Uma análise importante foi feita em Raz-Yurovich (2012), que estudou as questões sobre a decisão doméstica de terceirizar trabalhos, considerando a família como uma unidade organizacional, à luz da Teoria dos Custos de Transação. Apesar disso, ao contrário do que se é observado no cenário empresarial, as questões de confiança, incerteza e desonestidade podem ser mais importantes na decisão de terceirizar do que a frequência e a especificidade.

\section{Metodologia}

A metodologia empregada nesta pesquisa se baseou no modelo desenvolvido por Neves et al. (2001) para o planejamento de canais de distribuição de alimentos e bebidas, e em Oliveira (2011), que avaliou os custos de transação dos produtos agrícolas no ambiente ferroviário.

As entrevistas foram realizadas com atores-chave da cadeia de grãos e biocombustíveis. Esta abordagem metodológica conhecida como rapid assessment, ou quick appraisal, foi aplicada por Ellman (1981), Kumar (1993), Dunn (1994) e Beebe (1995), que usam dados de fontes secundárias junto a entrevistas semiestruturadas com os atores chaves da cadeia. Esta metodologia pode ser aplicada em pesquisas em que é necessário obter dados e/ou informações mais detalhadas para compreender a dinâmica do setor avaliado.

O rapid assessment é um método de coleta de dados que visa fornecer as informações necessárias de maneira objetiva e econômica. O método fornece as opiniões e feedbacks dos stakeholders e outras partes interessadas, a fim de responder à necessidade de informação sobre um determinado problema de pesquisa.

As entrevistas foram realizadas em julho/2016, com 20 especialistas de tradings que atuam nas atividades de exportação de soja e etanol no porto de Santos. Foram enviados formulários estruturados para identificar, interpretar e analisar os custos de transação, especificamente quanto à especificidade dos ativos (Anexo A). Os especialistas entrevistados foram representantes de grandes empresas, dentre os quais podemos citar: a Petrobras (empresa multinacional brasileira de economia mista da área de energia) e o grupo Caramuru (trading brasileira que atua na comercialização de commodities agrícolas). O grupo Caramuru também se destaca pela logística de transporte de produtos e grãos, com expressivos investimentos no porto de Santos.

Os formulários empregados na pesquisa foram estruturados com questões que trataram da especificidade dos ativos. O nível de especificidade foi classificado em uma escala que variou entre baixo, médio ou alto.

Posteriormente, a escala foi transformada em valores que variaram de 1, para uma para uma classificação "baixo", a 3, para uma classificação "alto", em intervalos unitários.

Para que as análises fossem realizadas, foi adotada a metodologia de cálculo do Índice de Custo De Transação (ICT) proposto por Oliveira (2011). Este índice envolve a transformação das cinco dimensões por ele contempladas quanto às especificidades dos ativos (físicos, temporal, ativos humanos, tecnológica e locacional). O número de atributos totais, ou seja, os itens avaliados dentre as diferentes especificidades, totalizou 34 atributos avaliados - quatro deles se aplica apenas para soja ou para etanol (Anexo A). 
Considera-se os seguintes parâmetros: $\mathrm{k}=\{1, \ldots, 34\}$ - conjunto do número de atributos avaliados e $x_{i}$ - valor atribuído ao atributo de especificidade i. Seja S - o somatório dos atributos de especificidade e ICT - o índice de custo de transação, que é determinado por:

$S=\sum_{i=1}^{k} x_{i}$

$I C T=100 \times \frac{S-k}{2 k}$

Na Equação 1, considerando o valor atribuído a cada atributo de especificidade $i$, determina-se o somatório total dos atributos de especificidades. A Equação 2 calcula o ICT relacionando o valor do somatório dos atributos de especificidade com o número de atributos de especificidade considerados.

O ICT representa a porcentagem, sobre o custo final da transação, despendida/imobilizada com os atributos das especificidades consideradas. Este índice pode variar de $0 \%$ a $100 \%$.

Para melhor posicionar o ICT encontrado para cada produto e apoiar a tomada de decisão dos agentes exportadores no desenho da forma de governança mais indicada, o índice foi classificado em três categorias, como ilustrado na Tabela 1.

Tabela 1. Classificação das categorias do Índice de Custo de Transação (ICT)

$\begin{array}{cc}\text { Classificação } & \text { Valor do ICT } \\ \text { Baixo } & 0-33,0 \% \\ \text { Médio } & 33,1 \%-66,0 \% \\ \text { Alto } & 66,1 \%-100,0 \%\end{array}$

ICT máximo:100\%; ICT mínimo: 0. Fonte: Dados da pesquisa (2017).

\section{Resultados e discussão}

O Índice do Custo de Transação (ICT) obtido para a soja e para o etanol estão reunidos na Tabela 2. O indicador foi construído a partir das diferentes dimensões das especificidades dos ativos, indicando para qual produto se tem maior custo de transação associado. Segundo Oliveira (2011), quanto mais exclusiva e especializada for a transação de um bem ou serviço, e quanto menos substituível este bem ou serviço for, maiores serão os custos de transação associados.

Para Belik et al. (2007), os ativos são ditos específicos quando eles não podem ser reempregados para outro uso sem que incorra em perdas de seus valores. Assim, quanto maior a especificidade maior será o ICT.

Tabela 2. Índice de Custo de Transação (ICT) para soja e etanol

$\begin{array}{ccc}\text { Especificidade de Ativos } & \text { Soja } & \text { Etanol } \\ \text { Especificidade de Ativos Físicos } & 11 & 20 \\ \text { Especificidade Temporal } & 4 & 2 \\ \text { Especificidade Tecnológica } & 30 & 32 \\ \text { Especificidade de Ativos Humanos } & 8 & 11 \\ \text { Especificidade Locacional } & 12 & 14 \\ \text { S }=\text { Somatório dos Atributos } & 65 & 79 \\ \text { ICT }=\text { Índice de Custo de Transação } & 45,6 \% & 66,2 \%\end{array}$

Fonte: Dados da pesquisa (2017). 
O maior ICT observado foi para o etanol (Tabela 2), indicando que o custo de transação associado ao processo de exportação desse produto via porto de Santos é maior, o que demanda estruturas de governança mais elaboradas, a exemplo de contratos de longo prazo e modelos de parceria, na tentativa de equalizar tais custos de transação. Com exceção da especificidade temporal, todas as demais observadas tiveram valor maior para o etanol.

O índice de $45,6 \%$ obtido para soja enquadra-se na classificação de médio ICT, enquanto que, para o etanol, o índice foi de 66,2\%, ficando na categoria de alto ICT.

Os custos de transação relacionados à especificidade locacional, apesar de estarem no mesmo nível de especificidade (Tabela 3), têm maior relevância quanto às atividades de exportação do etanol, isso porque, como já apontava Neves et al. (2001), os ativos envolvidos possuem, devido a características de transporte do produto transacionado, restrições locacionais e devem estar próximos para que a transação se efetue com sucesso. Assim, o etanol tem necessidade maior para ser armazenado e manuseado perto do porto e do cais, enquanto que a soja tem demanda menor.

Tabela 3. Especificidade locacional de ativos

\begin{tabular}{ccc} 
Tipo de Investimento em Ativos & \multicolumn{2}{c}{ Nível de Especificidade } \\
Necessidade de proximidade do cais & Soja & 2 \\
Necessidade de proximidade do porto & 1 & 2 \\
Necessidade de proximidade da ferrovia & 1 & 2 \\
Necessidade de proximidade do centro produtor & 3 & 3 \\
Fornecimento de energia & 2 & 3 \\
Fornecimento de água & 3 & 2 \\
Total & 2 & 14 \\
\hline
\end{tabular}

Fonte: Dados da pesquisa (2017).

Os ativos físicos envolvidos no processo de exportação do etanol também apresentaram maior especificidade (Tabela 4). Como já afirmava Neves et al. (2001), os ativos envolvidos na transação de um produto podem ser mais ou menos específicos, uma vez que permitem uma realocação mais ou menos custosas para outras atividades.

Os investimentos feitos em armazenagem em tanques para a do etanol são maiores e a sua realocação outras atividades é muito custosa. O etanol também exige sistemas de dutos de bombeamento, carregamento e descarregadores de navios específicos para o seu manuseio. Essas características contribuem para que o nível de especificidade dos ativos físicos envolvidos nas atividades de exportação do etanol seja alto e de difícil realocação para outras atividades.

Isso é diferente do que ocorre para a soja, uma vez que a estrutura e os investimentos feitos no porto e no cais do porto para exportação deste produto podem ser mais facilmente realocados para exportação de outro produto a granel. Esta operação já acontece, e as tradings usam os mesmos terminais e seus ativos físicos para transacionar milho, por exemplo.

Tabela 4. Especificidade de ativos físicos

\begin{tabular}{ccc} 
Tipo de Investimento em Ativos & \multicolumn{2}{c}{ Nível de Especificidade } \\
Instalações Físicas & & Etanol \\
Armazenagem (Silo/ Armazém/ Tancagem) & 1 & 3 \\
Facilidade de estocagem & 2 & 2 \\
Centro de serviços e reparos & 3 & 3 \\
\hline
\end{tabular}


Tabela 4. Continuação...

\section{Tipo de Investimento em Ativos}

\author{
Pátio de armazenagem \\ Tombador \\ Esteira transportadora \\ Balança e Moega
}

Sistema de Bombeamento

Duto para carregamento/descarregamento

Medidor de vazão

Instalações Móveis/Equipamentos

(Des) Carregador de Navio

Total
Nível de Especificidade

Soja

Etanol

1

1

3

$\mathrm{n} / \mathrm{a}$

$1 \mathrm{n} / \mathrm{a}$

$1 \mathrm{n} / \mathrm{a}$

$\mathrm{n} / \mathrm{a} \quad 2$

n/a 3

$\mathrm{n} / \mathrm{a}$

1

11

Fonte: Dados da pesquisa (2017).

Em geral, a especificidade de ativos humanos (Tabela 5) é um importante componente da transação. Este resultado se deve ao fato de que as pessoas que trabalham nas atividades de exportação de produtos agrícolas, necessitam de treinamento técnico específico, conhecimento operacional e sobre o produto movimentado, conhecimento dos processos específicos para exportação e precisam estar em constante aperfeiçoamento profissional. Considerando-se um alto nível de especificidade, deve-se analisar os riscos da falta de um efetivo nas atividades, dificultando a gestão dos processos e acarretando em maiores custos de transação, o que poderia elevar ainda mais o ICT.

Tabela 5. Especificidade de ativos humanos

\begin{tabular}{ccc} 
Tipo de Investimento em Ativos & \multicolumn{2}{c}{ Nível de Especificidade } \\
Treinamento da mão de obra técnica & Soja & Etanol \\
Necessidade de conhecimento do processo de operação & 1 & 3 \\
Necessidade de conhecimento do produto & 2 & 3 \\
Necessidade de conhecimentos de trading & 2 & 3 \\
Total & 3 & 2 \\
\hline
\end{tabular}

Fonte: Dados da pesquisa (2017).

Com já afirmava Neves et al. (2001), a análise da especificidade temporal tem mais relação com o produto transacionado, e leva em conta, principalmente, sua perecibilidade. A partir da Tabela 6, a especificidade temporal da soja é maior, haja visto que é um produto perecível, enquanto o etanol não. A soja exige frequência maior de embarque e desembarque e, ainda, uma gestão do tempo de armazenagem do produto, acarretando em especificidade temporal maior.

Tabela 6. Especificidade temporal

\begin{tabular}{|c|c|c|}
\hline \multirow{2}{*}{ Tipo de Investimento em Ativos } & \multicolumn{2}{|c|}{ Nível de Especificidade } \\
\hline & Soja & Etanol \\
\hline Tempo de armazenagem (perecibilidade) & 2 & 1 \\
\hline Embarque-desembarque frequente/transit time & 2 & 1 \\
\hline Total & 4 & 2 \\
\hline
\end{tabular}

Fonte: Dados da pesquisa (2017). 
De forma geral, a especificidade tecnológica é média nas atividades relacionadas tanto à exportação da soja quanto do etanol (Tabela 7), pois há a necessidade rastreamento dos produtos via Siscomex (Sistema Integrado de Comércio Exterior) desde a entrada no porto até a exportação. A partir da Lei de Modernização dos Portos houve a necessidade de integração entre os agentes exportadores, a Receita Federal e o Controle de Segurança dos Portos, coordenado pela Codesp (Companhia Docas do Estado de São Paulo).

Ademais, importadores, como a China, têm exigências especiais como registro junto às autoridades competentes do país, feito através do Mapa (Ministério da Agricultura, Pecuária e Abastecimento) - já os países da União Europeia exigem um rastreamento da carga. O etanol, por sua vez, deve ser registrado via Siscomex junto à ANP (Agência Nacional do Petróleo). Estas necessidades sistêmicas fazem com que o grau de especificidade seja semelhante para os dois produtos.

Tabela 7. Especificidade de ativos relacionados à tecnologia de informação e processos

\begin{tabular}{ccc} 
Tipo de Investimento em Ativos & \multicolumn{2}{c}{ Nível de Especificidade } \\
Investimento em troca eletrônica de dados & Soja & Etanol \\
Com Codesp & 2 & 2 \\
Com Receita Federal & 3 & 3 \\
Com Agência de Navegação & 2 & 2 \\
Com Dono da carga & 2 & 2 \\
Processo de gestão por categorias de produtos & & 3 \\
Equipe & 2 & 3 \\
Armazém separado & 3 & 2 \\
Processo de gestão por cliente & 1 & $\mathrm{n} / \mathrm{a}$ \\
Processo de fumigação & 2 & 1 \\
Processo de tancagem distinto & $\mathrm{n} / \mathrm{a}$ & 3 \\
Informação acompanhada junto ao produto & 2 & 32 \\
Processo de planejamento de logística conjunta & & 1 \\
Com Codesp & 1 & 3 \\
Com Transportadora & 2 & 3 \\
Com Dono da carga & 3 & 3 \\
\hline Trogramas de qualidade (certificações) & 2 & 3 \\
\hline
\end{tabular}

Fonte: Dados da pesquisa (2017).

\section{Conclusões}

A Teoria dos Custos de Transação é um assunto bastante explorado na literatura, desde Coase (1937), passando pelas contribuições de Williamson (1985), North (1990), Zylbersztajn (1996) e Neves et al. (2001). A questão que se coloca é a necessidade de que estes conceitos, tão importantes para a gestão organizacional das empresas, sejam estudados e analisados de forma aplicada em estudos de caso e, mais importante ainda, que sejam utilizados de forma prática pelas organizações modernas, assim como as pesquisas com aplicações já citadas neste trabalho.

A utilização de indicadores como o ICT na construção da tomada de decisão é cada vez mais importante, haja visto que em um cenário competitivo a escolha por arranjos contratuais para auxiliar a transações comerciais apresenta-se como fator decisivo de competitividade. Isso se confirma considerando o cenário atual, onde a empresa competitiva deve ser eficiente 
e efetiva, produzindo mais e com mais qualidade, mantendo ou reduzindo custos de produção e transação.

É possível observar que a maioria das especificidades dos ativos se encontram entre média e alta especificidade, indicando que a operação portuária é uma atividade com grande potencial de gerar altos custos de transação, fazendo que formas de governança mais adequadas aos produtos agropecuários sejam elaboradas.

Com base no ICT calculado é desejável a utilização de contratos de médio e longo prazo ou modelo de parceria na gestão organizacional das atividades de exportação, sobretudo do etanol. Neste caso, mesmo que os custos de transação sejam maiores inicialmente, estes arranjos contratuais mais elaborados e completos podem mitigar o comportamento oportunista e incerteza nas relações contratuais, regulando assim o ICT inerente a gestão destes ativos específicos.

Para as atividades de exportação de soja, os contratos de curto prazo se tornam mais atraentes, uma vez que arranjos contratuais muito elaborados e de longo prazo, podem ser custosos sem o retorno desejado.

Este trabalho se concentrou em estudar a especificidade dos ativos, que é um dos parâmetros das transações contratuais observadas por Williamson (1985). Portanto há a oportunidade de estudar os outros dois parâmetros das transações contratuais para a análise dos custos de transação, sendo eles a frequência e a incerteza das transações. A aplicação da NEl para analisar as atividades de exportação de outros produtos agropecuários apresentase como uma nova oportunidade, afim de ampliar o escopo de estudos aplicados sobre a TCT.

\section{Referências}

Azevedo, P. F. (2000). Nova economia institucional: referencial geral e aplicações. Revista Agriculta em São Paulo, 47(1), 33-52.

Beebe, J. (1995). Basic concepts and techniques of rapid appraisal. Human Organization, 54(1), 42-51.

Belik, W., Reydon, B. P., \& Guedes, S. N. R. (2007). Instituições, ambiente institucional e políticas agrícolas. In P. Ramos (Org.), Dimensões do agronegócio brasileiro: políticas, instituições e perspectivas (pp. 103-136). Brasília: Ministério do Desenvolvimento Agrário.

Brasil. (1993). Lei n 8.630, de 25 de fevereiro de 1993. Dispõe sobre o regime jurídico da exploração dos portos organizados e das instalações portuárias e dá outras providências. Diário Oficial [da] República Federativa do Brasil, Brasília. Recuperado em 4 de fevereiro de 2017, de http://www.planalto.gov.br/ccivil_03/leis/L8630.htm

Brasil. (2013a). Lei n 12.815, de 5 de junho de 2013. Dispõe sobre a exploração direta e indireta pela União de portos e instalações portuárias e sobre as atividades desempenhadas pelos operadores portuários. Diário Oficial [da] República Federativa do Brasil, Brasília. Recuperado em 4 de setembro de 2017, de http://www.planalto.gov.br/ccivil_03/_ato2011-2014/2013/lei/l12815.htm

Brasil. Ministério da Agricultura, Pecuária e Abastecimento. (2013b). Plano agrícola e pecuário 20132014. Recuperado em 4 de fevereiro de 2017, de http://www.agricultura.gov.br/assuntos/sustentabilidade/plano-agricola-e-pecuario/

Coase, R. H. (1937). The nature of the firm. Economica, 4(16), 386-405.

Companhia Docas do Estado de São Paulo - CODESP. (2016). Relatório de desempenho - estatísticas. Recuperado em 16 de fevereiro de 2017, de http://189.50.187.200/docpublico/amf_cpt/2016/amf2016-12.pdf

Dunn, T. (1994). Rapid rural appraisal: a description of the methodology and its application in teaching and research at Charles Sturt University. Rural Society Journal, 4(3/4), 30-36.

Ellman, A. (1981). Rapid appraisal for rural project preparation. Agricultural Administration, 8, 463-471.

Farranha, A. C., Frezza, C. S., \& Barbosa, F. O. (2015). Nova Lei dos Portos: desafios jurídicos e perspectivas de investimentos. Revista Direito GV, 11(1), 89-116.

Fernandes, R. A. S. (2009). A suinocultura de Minas Gerais sob o enfoque da economia dos custos de transações. Custos e @gronegócio on line, 5(3), 88-103.

Fragoso, R. M. S. (2013). Planning marketing channels: case of the olive oil agribusiness in Portugal. Journal of Agricultural \& Food Industrial Organization, 11(1), 51-67.

Hilsdorf, W. C., \& Nogueira Neto, M. S. (2016). Porto de Santos: prospecção sobre as causas das dificuldades de acesso. Gestão \& Produção, 23(1), 219-231. 
Ji, C., Felipe, I., Brizc, J., \& Trienekens, J. H. (2012). An empirical study on governance structure choices in China's pork supply chain. The International Food and Agribusiness Management Review, 15(2), 121 152.

Kumar, K. (1993). Rapid Appraisal method (203 p.). Washington: World Bank. Recuperado em 10 de fevereiro de 2017, de http://documents.worldbank.org/curated/pt/888741468740959563/pdf/multiOpage.pdf

Leme, M. F. P., \& Zylbersztajn, D. (2008). Determinantes da escolha de arranjos institucionais: evidências na comercialização de fertilizantes para soja. Revista de Economia e Sociologia Rural, 46(2), 517-546.

Martins, R. S., Xavier, W. S., \& Sproesser, R. L. (2010). Custos de Transação nas operações de exportação de café na região sul de minas gerais. Organizações Rurais \& Agroindustriais, 12(3), 411-422.

Neves, M. F., Zuurbier, P., \& Campomar, M. C. (2001). A model for the distribution channels planning process. Journal of Business and Industrial Marketing, 16(7), 518-539.

Nogueira, A. C. L., \& Bataglia, W. (2012). Transaction costs and organizational competences: explaining the governance structure for manufacturing stage. Journal of Technology Management \& Innovation, $7(1), 159-174$.

North, D. C. (1990). Institutions. In D. C. North, R. Calvert \& T. Eggertsson. Institutions, Institutional Change and Economic Performance (159 p.). Cambridge: Cambridge University Press.

Nuintin, A. A., Curi, M. A., \& Santos, A. C. (2012). Characterization and analysis of transactions resulting from the employment of labor in the coffee activity from the optical in the of Transaction Cost Economy. Custos e @gronegócio on line, 8(3), 70-90.

Oliveira, A. L. R. (2011). Transporte ferroviário de produtos agrícolas sob a ótica da Economia dos Custos de Transação: algumas experiências. Informações Econômicas, 4(11), 35-48.

Raz-Yurovich, L. (2012). Application of the transaction cost approach to households - the demographics of Households' 'Make or Buy' Decisions (No. 25, 54 p., Working Paper). Rostock: Max Planck Institute for Demographic Research. Recuperado em 16 de julho de 2017, de http://www.demogr.mpg.de/papers/working/wp-2012-025.pdf

Schwab, K. (2016). The Global Competitiveness Report 2016-2017. Geneva: World Economic Forum. Recuperado em 16 de julho de 2017, de http://www3.weforum.org/docs/GCR20162017/05FullReport/TheGlobalCompetitivenessReport2016-2017_FINAL.pdf

Weseen, S., Hobbs, J. E., \& Kerr, W. A. (2014). Reducing hold-up risks in ethanol supply chains: a transaction cost perspective. The International Food and Agribusiness Management Review, 17(2), 83106.

Williamson, O. E. (1979). Transaction-cost economics: the governance of contractual relations. The Journal of Law \& Economics, 22(,2), 233-261.

Williamson, O. E. (1985). Transaction cost economics. The economic institutions of capitalism (pp. 15-42). Nova lorque: The Free Press.

Williamson, O. E. (1991). Comparative economic organization: the analysis of discrete structural alternatives. Administrative Science Quarterly, 36, 269-296.

Williamson, O. E. (1993). Opportunism and its critics. Managerial and Decision Economics, 14(2), 97-107.

Williamson, O. E. (2007). Transaction-cost economics: an introduction (No. 3, 32 p., Economics Discussion Papers). Recuperado em 2 de fevereiro de 2017, de http://www.economicsejournal.org/economics/discussionpapers/2007-3

Zylbersztajn, D. (1996). Governance structures and agribusiness coordination: a transaction cost economics based approach. Research in Domestic and International Agribusiness Management, 12, 245-310.

Zylbersztajn, D. (2014). Coordenação e governança de sistemas agroindustriais. In A. M. Buainain, E. Alves, J. M. F. J. Silveira \& Z. Navarro (Orgs.), O mundo rural no Brasil do século 21: a formação de um novo padrão agrário e agrícola (Vol. 1, pp. 267-294). Brasília: Embrapa. 


\section{Anexo A. Questionários enviados aos agentes}

Tabela 1. Especificidades de ativos físicos: equipamentos, infraestrutura e facilidades.

Tipo de Investimento em Ativos
Instalações Físicas
Armazenagem (Silo/ Armazém/ Tancagem)
Facilidade de estocagem
Centro de serviços e reparos
Pátio de armazenagem
Tombador
Esteira transportadora
Balança e Moega
Sistema de Bombeamento
Medidor de vazão
Instalações Móveis/Equipamentos
(Des) Carregador de Navio
Total

Nota: O objetivo da Tabela 1 é identificar quão específica foi a infraestrutura construída/adquirida para atender a exportação do produto analisado. Neste item há duas divisões: instalações fixas e móveis. A classificação pode variar entre baixa, média e alta especificidade dos ativos envolvidos.

Tabela 2. Especificidade temporal: pressão de tempo/agilidade para realizar a transação.

$\begin{array}{ccc}\text { Tipo de Investimento em Ativos } & \text { Nível de Especificidade } \\ \end{array}$

Tempo de armazenagem (perecibilidade)

Embarque-desembarque frequente/transit time

Total

Nota: O objetivo da Tabela 2 é identificar o quanto a natureza do produto, no caso a perecibilidade, afeta a comercialização no que tange o período de armazenagem da carga e na operação (embarque e desembarque). A classificação pode variar entre baixa, média e alta especificidade dos ativos envolvidos.

Tabela 3. Especificidade de ativos relacionados à tecnologia de informação e processos.

Tipo de Investimento em Ativos
Investimento em troca eletrônica de dados
Com Codesp
Com Receita Federal
Com Agência de Navegação
Com Dono da carga
Processo de gestão por categorias de produtos
Equipe
Armazém separado
Equipamentos distintos
Processo de gestão por cliente


